\title{
A meta-analysis on the nutritional value of insects in aquafeeds
}

\author{
N.S. Liland ${ }^{1 *}$, P. Araujo ${ }^{1}$, X.X. Xu ${ }^{1,2}$, E.-J. Lock ${ }^{1,3}$, G. Radhakrishnan ${ }^{1,3}$, A.J.P. Prabhu ${ }^{1}$ and I. Belghit ${ }^{1 *}$ \\ ${ }^{1}$ Institute of Marine Research, P.O. Box 1870 Nordnes, 5817 Bergen, Norway; ${ }^{2}$ College of Animal Science and Technology, \\ Northwest AEF University, Yangling 712100, Shaanxi, China, P.R.; ${ }^{3}$ Department of Biology, University of Bergen, Postbox \\ 7803, 5020 Bergen, Norway; nina.liland@hi.no; ikram.belghit@hi.no
}

Received: 17 November 2020 / Accepted: 22 May 2021

(c) 2021 Wageningen Academic Publishers

OPEN ACCESS C(1) (8) REVIEW ARTICLE

\begin{abstract}
A major challenge for development of sustainable aquafeeds is its dependence on fish meal and fish oil. Similarly, it is unwanted to include more plant ingredients which adds more pressure on resources like arable land, freshwater and fertilisers. New ingredients that do not require these resources but rather refine and valorise organic side streams, like insects, are being developed. Increasing evidence indicates that using insect ingredients in aquafeeds are a sustainable alternative and considerable progress has been made on this topic in the past years. The aim of this chapter is to present a comprehensive and systematic analysis of the data available on the impact of insects in aquafeeds. Systematic search, collection and selection of relevant literature from databases such as Web of Science and NCBI was performed. The literature search enabled 91 scientific papers from peer-reviewed journals, comprising a dataset of 415 experimental diets, including 35 different aquatic species and 14 insect species to be included in this meta-analysis, covering what we consider a close to complete representation of credible publications on this topic. Information on aquatic species, insect species, dietary composition (amino acids, fatty acids, proximate composition) and performance outputs (growth performance indicators and nutrient digestibility) were included in the construction of the dataset. Regression models and principal component analyses were performed on the meta-data. The results from the meta-analysis revealed a great degree of variation in the maximum threshold for insect inclusion in aquafeeds (from 4 to $37 \%$ ) based on subgroups of trophic level of aquatic species, insect species used, statistical method and the output parameter. Overall, a maximum threshold of $25-30 \%$ inclusion of insects in aquafeeds for uncompromised performance is suggested. Reduction in protein digestibility, imbalanced amino acid profile and increasing levels of saturated fatty acid were identified as major factors limiting higher inclusion of insects in aquafeeds.
\end{abstract}

Keywords: aquafeed, aquaculture, black soldier fly, mealworm, sustainable feed

\section{Introduction}

By 2050, the world population is expected to reach 9.7 billion (UN, 2019), and the demand for feed and food crops is expected to increase to $25-70 \%$ above today's levels. Aquaculture is currently producing more than half of the seafood destined for human consumption and is considered by the FAO as having the capacity to grow and become an even more important source of animal protein for the expanding world population (FAO, 2020). Around 70\% of the total aquaculture production today is made up of fed species, and the aquafeed industry must therefore keep up with this growth. Many of the traditional non-fed forms of finfish aquaculture are also being intensified, often resulting in the use of formulated feeds, thus putting a further pressure on the production of aquaculture feeds. With a lot of pressure on land- and water-use by agriculture, and an already maximised output from most fisheries, the aquafeed industry is looking for new sources for feed ingredients with a smaller impact on the global environment and resource use.

Due to a limited availability of fish meal (FM) and fish oil (FO), there has already been a considerable reduction in the inclusion level of such marine ingredients in aquafeeds during the last two decades. A large amount of research 
lies behind this shift in dietary composition, which has focused on the nutritional requirements of each fish species (Glencross, 2020; Glencross et al., 2007; Turchini et al., 2019). The main ingredients in most aquafeeds nowadays are from terrestrial sources, dominated by plant-derived products such as soy protein concentrates and different vegetables oils, as well as animal by-products, depending on the region and fish species (FAO, 2011). While the replacement of FM and FO with terrestrial ingredients has allowed the sector to grow, some of these aquafeed ingredients could be used directly for human consumption. Additionally, by sourcing feedstuffs from agriculture, there is a risk of contributing to the global deforestation and a non-sustainable resource consumption (Wilfart et al., 2016). The current research is therefore focused on finding novel sources of ingredients to replace both traditional marine and plant-based ingredients. Most research has considered animal by-products, microalgae, single cell proteins, blue mussels, krill and insects (Hua et al., 2019; Sørensen et al., 2012).

The first report of rearing insect dates back to thousands of years ago when the cultivation of silkworms (Bombyx mori) for silk production was initiated in China. Insects have also been an important protein source for people in many cultures (Evans et al., 2015). The earliest published research on the use of insects to convert animal waste into high quality protein to then be used in animal feeds, appeared in the 1970s (Hale, 1973; Newton et al., 1977). In these trials, the authors included black soldier fly (BSF) larvae (Hermetia illucens), reared on cattle faeces and urine slurry, as a dietary supplement for chicken and swine. Later, the larvae of this fly species was tested as a feed ingredient in the diets of channel catfish and tilapia (Bondari and Sheppard, 1981). A more industrialised farming of insects for feed purposes started in Western countries in the last decade, accompanied by a large amount of research on the use of this feed ingredient in animal diets (Van Huis, 2020a,b). Since then, the interest in using insects in fish nutrition has increased exponentially, leaving a large amount of data from scientific studies (e.g. Arru et al., 2019; Gasco et al., 2019; Henry et al., 2015; Hua, 2021; Nogales-Mérida et al., 2019). Insect meals (IM) have a great potential for supplying the protein required for future aquafeed production. There has therefore been a strong support for research and industries in connection with available insect processing, upscaling production and cost (Hua et al., 2019; IPIFF, 2019a,b, 2020a). There is today an increase in companies focusing on the farming of insect species on a large scale (Cadinu et al., 2020; IPIFF, 2019a,b, 2020b). In 2017, the European Union authorised the use of processed IMs from seven insect species (BSF, common housefly, yellow mealworm, lesser mealworm, house cricket, banded cricket and field cricket - EU, 2017) in aquafeeds. One year later, the first insect-fed rainbow trout was seen in the French market. The aquaculture sector consumed more than $50 \%$ of the total European insect protein production in 2019, which was approximatively 5,000 tons (IPIFF, 2019b). Both the insect production and the use of insect products in aquafeeds are predicted to rise (IPIFF, 2019b). However, despite the great progress in research on the topic and large growth in insect production, insects are currently not produced in sufficient volumes to be used more extensively in commercial aquafeed production.

Scientific literature concerning the nutritional properties of different insect species and the use of insect-based ingredients in aquafeed have been extensively reviewed (Gasco et al., 2019; Henry et al., 2015; Hua, 2021; NogalesMerida et al., 2019). Dietary inclusion of insect protein meal and/or insect oil in aquaculture diets without negative effect on growth performances have been successfully demonstrated in some feeding trials (Belghit et al., 2019a; Bruni et al., 2020; Fawole et al., 2020; Li et al., 2017; Magalhães et al., 2017; Wang et al., 2019). However, in other studies, growth performance and feed utilisation were repressed by using insects in the diets (Gasco et al., 2016; Kroeckel et al., 2012; Reyes et al., 2020). The variations in growth and feed utilisation seen between the studies might be due to differences in tolerance level of insect ingredients between aquatic species and life stages. Logically, the quality of the insect ingredient utilised will also play a large role, as the quality of this ingredient varies due the insect species, nutritional profile, use of different rearing substrate and the processing methods. A vital part of how well insect ingredients will perform in a compound diet is the production and composition of the diet. The living conditions for the aquatic species are also important, so factors such as water quality and general care for the aquatic species can also affect the results. The large amount of research done on the use of insects as aquafeed ingredients, makes it hard to see the general tendencies concerning what might be more or less successful when using insects as part of a compound feed. One way of achieving a comprehensive inter-study comparison of the available data is to perform a meta-analysis. The quantitative evaluation of input (e.g. diet composition) and output (e.g. growth) by different mathematical and statistical approaches (e.g. univariate/ multivariate analysis) might allow for a better understanding of the most influential parameters affecting the performance of aquatic species fed diets containing insects.

Meta-analysis studies have gained recognition in many scientific fields, including the field of fish nutrition, as a useful tool to obtain more knowledge of the existing published data. This approach has been used to analyse data on dietary requirements for amino acids (AA) and minerals in fish (Kaushik and Seiliez, 2010, Prabhu et al., 2013; 2016), and for evaluating the effects of FM replacement with alternative protein sources in fish diets (Hua, 2021; Hua and Bureau, 2012). Recently, Hua (2021) employed a meta-analysis to quantify the relationship between FM 
replacement with IM in aquafeeds and growth performance (specific growth rate - SGR) of different aquatic species. In this study, based on 33 published trials, the author concluded that low or moderate replacement of FM with IM (below 29\% of diet) had no effects on fish growth performance. The author highlights the importance for further research to elucidate the different biological and dietary factors that influence tolerance levels of IM in the diets of farmed aquatic species.

This chapter aims to summarise the current knowledge on the use of insects in aquaculture feeds by performing a meta-analysis. We wanted to search for nutritional factors of diets containing insect ingredients that affect the performance of the aquatic species. In addition, we wanted to give a comprehensive overview over existing studies on the use of insects in aquafeeds. We have gathered detailed information on diet composition (AA, fatty acids (FA), and proximate composition) as well as several growth performance parameters (such as SGR and feed conversion ratio (FCR)). This information was used for a meta-analysis to search for patterns in what factors cause changes in performance. In addition, we provide the complete dataset which can be a useful tool for future studies, both for planning and for comparing results.

\section{Methods}

\section{Literature search}

A systematic literature search was conducted through the electronic databases Web of Science and NCBI in October 2020, using a combination of search terms (insect OR dietary insect OR H. illucens OR Tenebrio molitor) AND (fish OR fish nutrition OR fish growth). Three peerreviewed articles in Chinese were also included in the metaanalysis. A first screening step was based on the title and abstract of each article. This procedure allowed for the exclusion of irrelevant studies according to the criteria listed below: (1) no data reported on the growth or on the feed intake; (2) study on ornamental aquatic species; and (3) using live insects or dietary frass from insect species in fish diets.

The initial search generated 165 articles. Among these, 12 duplicates and 62 studies not fitting the criteria were removed, leaving 91 relevant articles for the meta-analysis.

\section{Selection of parameters to include in meta-analyses}

The data selection was based on the most reported parameters in published studies. We also chose parameters that we knew are generally analysed by the same or similar methods, to allow for better comparison. The nature of data collected is summarised in Table 1. It must be mentioned that some data not intended for meta-analysis (e.g. crude protein and lipid of the IMs and their AA composition) were also collected and included as a separate supplementary table (Table S1). The complete data set used in the metaanalysis study is also presented in Table S1.

\section{Aquaculture species included in the meta-analysis}

The meta-analysis included 91 studies in peer-reviewed manuscripts where insect meals or oils were used in diets for aquatic species. The studies were performed on 35 different species of fish and shellfish. The main species cited were Rainbow trout (16 papers) and Nile tilapia (9 papers). A complete overview of the species used in the studies is found in Table S2. The feeding ranged in days from 12 to 163 with a median at 56 days (Table S1). The trial lasting 12 days was not a growth trial and only recorded for nutrient digestibility. There was a large range in the size of aquatic species used in the trials $(1 \mathrm{~g}-3.7 \mathrm{~kg}$ final body weight), although most of the studies were done on juvenile aquatic species. The median of final body weights was at $62 \mathrm{~g}$ and $68 \%$ of the 378 dietary groups were from aquatic species with a final body weight lower than $100 \mathrm{~g}$. We checked the data reported about trial execution in each trial and found that most trials were performed according to physical and nutritional needs of each species. Some exceptions were found, such as a trial with European seabass performed in temperatures in the upper tolerance range of this species (27-28 ${ }^{\circ} \mathrm{C}$, Abdel-tawwab et al., 2020), and yellow catfish (up to $32^{\circ} \mathrm{C}$, Hu et al., 2017), but none where they exceeded the tolerance range (Table S1).

\section{Insect species and products included in the meta- analysis}

Most of the experimental trials used BSF as a feed ingredient, representing $46 \%$ of the diet groups of the full data, followed by yellow mealworm (MW, T. molitor), including superworm (Zophobas morio), with $32 \%$ of the data, silkworm (B. mori) accounting for $13 \%$ of the data, housefly (Musca domestica) with $8 \%$ and the remaining $1 \%$ of the studies being done on tropical house cricket (Gryllodes sigillatus), field cricket (Gryllus assimilis), Turkestan cockroach (Blatta lateralis), speckled cockroach (Nauphoeta cinerea), Madagascar hissing cockroach (Gromphadorhina portentosa), green bottle fly (Lucilia sericata Meigen), shea caterpillar (Cirina butyrospermi), nonbiting midges (chironomid) and grasshoppers (locust). Insect meals and oils included were from in total 14 different species (Table S3). The collected data includes studies done with 105 different dried IMs, 7 different insect oils, 3 protein hydrolysates, 1 fermented product and 2 products using wet, ground insect products. Most of the studies are performed on dry insect meals, either used as is or with different degrees of defatting. A complete overview of the insect species and citing papers can be found in Table S3. 
Table 1. An overview of the extracted data from the selected 91 papers. ${ }^{1}$

\begin{tabular}{|c|c|}
\hline & Input data - diets \\
\hline \multirow[t]{3}{*}{ Input data - aquatic species and trials } & - Aquatic species \\
\hline & - Developmental stage of aquatic species \\
\hline & - Length of trial (days) \\
\hline \multirow[t]{6}{*}{ Input data - insect ingredients } & - Insect species \\
\hline & - Insect developmental stage (larvae, pre-pupae, pupae, adult insect) \\
\hline & - Substrate used to grow insects \\
\hline & - Type of product/processing \\
\hline & - Insect proximate composition (crude protein, ether extract, ash, dry matter as $\%$ of insect product) \\
\hline & $\begin{array}{l}\text { - Insect content of essential and semi-essential AAs (Arg, His, Ile, Leu, Lys, Met, Phe, Thr, Trp, Val, Ala, } \\
\text { Glu, Tau as \% of protein) }\end{array}$ \\
\hline \multirow[t]{4}{*}{ Input data - dietary composition } & - Diet proximate composition (crude protein, ether extract, ash, dry matter as \% of diet) \\
\hline & - Inclusion level of insect product in diet (\% of diet) \\
\hline & $\begin{array}{l}\text { - Dietary essential and semi-essential AAs (Arg, His, lle, Leu, Lys, Met, Phe, Thr, Trp, Val, Ala, Glu, Tau } \\
\text { as \% of diet) }\end{array}$ \\
\hline & $\begin{array}{l}\text { - Dietary content of selected FA (lauric acid, EPA, DHA, sum saturated FA, sum polyunsaturated FA as } \% \\
\text { of total FA and ratio n-3/n-6 FA) }\end{array}$ \\
\hline \multirow[t]{5}{*}{ Output data - aquatic species performance } & - Initial body weight in grams \\
\hline & - Final body weight in grams and normalised per study (control set to $100 \%$ ) \\
\hline & - Feed conversion ratio ${ }^{2}$ \\
\hline & - Digestibility of crude protein and lipid \\
\hline & - Specific growth rate ${ }^{3}$ \\
\hline${ }^{1} \mathrm{AA}=$ amino acids; $\mathrm{DHA}=$ docosahexaenoic $\mathrm{a}$ & acid; EPA = eicosapentaenoic acid; FA = fatty acid. \\
\hline${ }^{2} \mathrm{FCR}=$ feed intake $(\mathrm{g}) /$ growth $(\mathrm{g})$ & (1) \\
\hline
\end{tabular}

\section{Composition of insect meals included in the meta-analysis}

The composition of IMs used for formulating the diets included in this meta-analysis is presented in Table 2. There was quite a large range in protein and lipid content, reflecting the different degrees of defatting performed on the insect ingredients. The average protein content was $52 \pm 12 \%$ of the meal, ranging from 24 to $83 \%$ of dry matter. The content of the typical limiting AAs lysine, threonine, methionine and tryptophane also varied a lot between the different meals (Table S1). The content of AAs in the insect meals is reported as \% of protein to reflect the quality of the protein in the meal, rather than the quantity, and to be able to compare between meals with large differences in protein content. Some insect meals contained essential AAs below the requirement of most aquatic species. Arginine was, for example, low in some full-fat BSF meals (Fabrikov et al., 2020; Józefiak et al., 2019b), while the content of this AA was higher in defatted mealworm and aquatic insects (Basto et al., 2020; Roncarati et al., 2019). The variations in AA composition, even within the same insect species and similar processing of the meal, emphasises the importance of analysing AA composition before the production of any insect-containing feed.

\section{Composition of experimental diets included in the meta- analysis}

We collected information on the proximate composition of diets used in the reported trials and compared to requirements of the aquatic species in question, when this was available (NRC, 2011). The average protein content of the experimental diets was $47 \pm 5 \%$ for salmonids, $46 \pm 5 \%$ for European seabass/seabream, $42 \pm 3 \%$ for catfish, $38 \pm 2 \%$ for shrimp, $36 \pm 3 \%$ for carp and $35 \pm 6 \%$ for tilapia. Dietary protein contents were all within protein requirements of respective species. Almost all the included studies fulfilled the requirements for the essential AA, except some studies where the levels of iso-leucine (Muin et al., 2017; SánchezMuros et al., 2015) and leucine (Devic et al., 2017) were below requirement for Nile tilapia (NRC, 2011). As seen from the references, the dietary deficiencies of AA were mostly found in Nile tilapia (Devic et al., 2017; Muin et al., 2017; Sanchez-Muros et al., 2015). Most trials therefore reported diets with sufficient AA contents.

The dietary lipid content also varied with aquatic species and were in according to general acceptance and requirement of lipids in the respective species. The average 
Table 2. The nutrient profile of the insect meals used for diet formulation in the studies included in the meta-analysis.

$\begin{array}{lcccc}\text { Parameters } & \begin{array}{l}\text { Range values } \\ \text { (min-max) }\end{array} & \text { Median } & \text { S.D. } & \text { Data points } \\ & & & & \\ \text { Proximate composition (\% of insect meal) } & 79-98 & 93 & 3.5 & 58 \\ \quad \text { Dry matter } & 24-83 & 52 & 12 & 87 \\ \quad \text { Crude protein } & 1.6-35 & 22 & 9.4 & 86 \\ \quad \text { Lipid } & & & 1.5 & 47 \\ \text { Concentration of selected essential amino acids (\% of crude protein) } & 2.3-9.2 & 5.2 & 1.0 & 47 \\ \quad \text { Lysine } & 1.5-6.4 & 3.5 & 0.7 & 47 \\ \quad \text { Threonine } & 0.6-3.9 & 1.4 & 1.3 & 0.4\end{array}$

lipid contents of the experimental diets were (in order of highest to lowest) $19 \pm 5 \%$ for salmonids, $15 \pm 5 \%$ for European seabass/seabream, $13 \pm 5 \%$ for catfish, $11 \pm 5 \%$ for tilapia, $9 \pm 5 \%$ for shrimp and $7 \pm 5 \%$ for carp. FA composition varied according to the use of FO and plant oils. The inclusion of the fat fraction of BSF meals led to an introduction of the medium chained FA lauric acid (C12:0) to the diets, which was found in levels as high as $33 \%$ of total FA (Kroeckel et al., 2012).

\section{Data analyses and statistics}

\section{Distribution of data}

The entries for control and insect inclusion in diets in Table S1 were labelled as -1 and 1 , respectively. The distributions in terms of FCR, SGR, digestibility of crude protein (DCP) and digestibility of crude lipid (DCL) were studied by setting the control diet as the reference distribution. The responses (FCR, SGR, DCP and DPL) were standardised by subtracting the mean $(\mu)$ from the control diets and dividing by its associated standard deviation $(\sigma)$.The results (Figure S1) demonstrated that the distributions for the control and insect inclusion diets overlapped according to a normal distribution $(\mu=0$ and $\sigma=1)$. Few responses for the control diets were outside the $99.9 \%$ area of the normal curve. For example, two FCR values and one SGR value were outside the range $\pm 3 \sigma$ (Figure S1). Although most of the responses in the insect inclusion diets overlapped with the control diets, the former diets showed that some FCR and SGR responses differed from the latter diet, probably due to the influence of the percentage of insect inclusion in the diets, which is a parameter studied in more detail below.

In this meta-analysis, few studies ( 12\%) reported four performance parameters (FCR, SGR, DCP and DCL) simultaneously, while the $70 \%$ of the studies were focused on reporting two performance parameters simultaneously, for instance FCR/SGR (65\%), DCP/DCL (3\%) or SGR/DCP (1\%).

\section{Regression analysis}

The meta-data collected, namely normalised final weight (NFW), FCR, SGR, DCP and DCL, were subjected to regression analyses. Linear regression was performed using the simple model $\mathrm{Y}=\mathrm{bX}+\mathrm{a}$, where $\mathrm{Y}$ is the output, $\mathrm{x}$ is the insect inclusion level in the diet, $\mathrm{b}$ is the slope and $\mathrm{a}$ is the intercept. Broken-line analyses with two slopes was used for non-linear regression. The broken-line regression used was: $\mathrm{Y} 1=\mathrm{a} 1+\mathrm{b} 1^{*} \mathrm{X} ; \mathrm{Yat} \mathrm{Xbp}=\mathrm{b} 1^{*} \mathrm{Xbp}+\mathrm{a} 1 ; \mathrm{Y} 2=\mathrm{Yat} \mathrm{Xbp}+\mathrm{b} 2 *(\mathrm{X}$ - Xbp); $\mathrm{Y}=\mathrm{IF}(\mathrm{X}<\mathrm{Xbp}, \mathrm{Y} 1, \mathrm{Y} 2)$ as described in Prabhu et al. (2013). In the above model, $X$ is the insect inclusion level in the diet as percent; Y1, Y2 are output measures; b1, b2 are slopes of the two regression segments; $\mathrm{a} 1, \mathrm{a} 2$, the intercepts and $\mathrm{Xbp}$ is the breakpoint which provides the estimated insect inclusion level at which the inflection in response was observed. The analysis was performed on three different constraint levels: no constraints, medium constraint $-0.2<\mathrm{b} 1<0$ and high constraint $-0.1<\mathrm{b} 1<0$. In addition to the broken line regression, simple quadratic regression was also tested. Regression analyses was performed on the entire dataset for each of the specified output measures and on sub-grouped datasets based on (1) trophic groups; (2) insect species groups and (3) AA supplemented vs nonsupplemented studies. For any dataset, both linear and non-linear regression analyses was performed, and the best fit model was chosen to describe the trend and parameter estimates such as slope, breakpoint or intercept. All the regression analyses were performed using GraphPad Prism ${ }^{\circ}$ (version 8.03 for Windows GraphPad Software, La Jolla, CA, USA).

Aquatic species group: The trophic level (TL) expresses the interactions of organisms with each other within their food web. The TL estimates of the aquatic species were taken from the Fish Base data (FishBase, www.fishbase.org; Froese and Pauly, 2007). The TL of fish generally range from 2 (e.g. the detritus feeding blue-barred parrotfish) to 4.7 (e.g. the piscivorous striped marlin), cephalopods from 3.2 (e.g. the 
planktivorous Patagonian squid) to 4.5 (e.g. the piscivorous greater hooked squid). Thus, the different aquatic species in the current study were categorised into two groups according to their TL, TL value above or below 3.5. The first category of aquatic species (TL $>3.5$ ) included blackspot seabream, Chum salmon, tench, seabream, African catfish, common catfish, largemouth bass, Japanese seabass, Asian seabass, rainbow trout, meagre, turbot, Atlantic salmon, red seabream, Olive flounder, gilthead seabream, black sea salmon, Eurasian perch and rockfish. The second category of aquatic species $(\mathrm{TL}<3.5)$ comprised Nile tilapia, rohu carp, gibel carp, field eel, rice field eel, jian carp, mirror carp, Siberian sturgeon, seatrout, yellow catfish, dark barbell catfish, European seabass and climbing perch. The third group included crustaceans which comprised Pacific white shrimp, giant freshwater prawn and marron. The pearl gentian grouper was excluded in this analysis as the TL of this species was not provided in Fish Base data.

Insect species group: The full data set was also divided into two subgroups based on the most studied insect species, being: (1) BSF (46\% of the data); and (2) MW (32\% of the data).

Amino acid supplementation: Two data sets were compiled using the full data set, each containing closely related aquatic species. The trials were then split into two: (1) trials where diets were supplemented with AAs (lysine and/ or methionine); or (2) trials with non-supplemented diets. The only groups that had enough data for a comparison of supplemented vs non-supplemented were trout (sea trout and rainbow trout combined, 9 trials with supplemented diets and 11 trials with non-supplemented diets) and the carnivore marine fish seabream and seabass combined (5 studies with supplemented diets and 7 trials with non-supplemented diets). The dietary inclusion of IM was plotted against the main output factors: normalised final body weight, SGR and FCR. Regression analyses were performed as described above to find the best fit line and to discover any significant relationships between inclusion level of insects in diets supplemented or not with AA. We also used a t-test to see if the two groups showed any different response. Outliers, clearly a result of either typographical errors or trials not being growth experiments, were not included (SGR in rainbow trout trials, Jeong et al., 2020; Gelincek and Yamaner, 2020).

\section{Principal component analysis}

The parameters summarised in Table S1 were arranged as a $m \times n$ data matrix, where $m$ represented the independent variables (e.g. aquatic species, percentage of inclusion, fish subgroups, etc) and $n$ represented the measured responses (e.g. FCR, SGR, DCP and DCL), and submitted to principal component analysis (PCA) to reduce the dimensionality of the data set. The matrices submitted to PCA are standardised by subtracting their means and dividing by their standard deviations to construct linear combinations of the predictor variables $n$ that contains the greatest variance. Statgraphics $19^{\circ}$ Centurion (Version 16.1.11, StatPoint Technologies, Inc., The Plains, VA, USA) was used for statistical analysis of the data set in Table S1.

\section{Results and discussion}

The aquaculture feed industry needs new sources of feed ingredients, and insects are on their way to become one of these novel sources of protein and fats. When overcoming the obstacle of production quantities, both insect protein and lipid should have a natural place in aquafeeds. This comprehensive overview of work performed on the use of insect ingredients in aquafeeds shows that a massive research effort has been focused on this topic, but that the studies in total have some shortcomings as they are almost all from quite small-size aquatic species. This might partially be due to the smaller cost related to feeding trials with smaller animals. The fact that production quantities are a limiting factor for the use of insects in aquafeeds might also have led to more studies being done on juvenile stages. These stages are less demanding for large quantities of feeds and feed ingredients than the grow-out phases, and, as such, an obvious starting place for implementing commercial insect-containing diets. Also, compared to commercial diets, feed prepared for research scale on small-size aquatic species are generally not extruded at high pressure and temperature. The demonstrated links between specific nutrients in the diets and growth performance shown here can be the basis for future studies. The attached data file containing all collected data from a total of 91 publications using insect ingredients in aquafeeds can also be helpful for planning future studies and for comparing results from future trials.

\section{Growth and performance impact of insect ingredients in aquafeeds}

Normalised final body weights were plotted against insect inclusion in diets. There were in total 87 control diets and 285 insect-containing diets included in this analysis. Of the 285,121 observations were higher, and 164 were lower than their respective controls (Figure 1A). In summary, we found that $58 \%$ of the insect-fed groups ended up with a final body weight below the control, and $42 \%$ showed a higher final body weight than their respective controls. Quite many of the studies using insect ingredients thus demonstrate a better growth than their respective controls, showing that making well-performing diets containing insect ingredients is quite possible. A quantitative estimation of the threshold inclusion of insect ingredients in the diets at which the growth performance started to decline was performed on the same data set. The breaking point estimated for low or little reduction in normalised final weight was at $25.0 \%$ 
insect inclusion in the diets (Figure 1A). The slope (b2) for the line after $25 \%$ insect inclusion was -0.42 (Figure 1A). Little effects on normalised final body weight were therefore found with up to $25 \%$ insects in the diets, with a gradual decrease in final weights obtained in the trials using higher dietary inclusion of insects. The same effect of a strong breaking point was not seen on the SGR, which showed a negative regression with increasing dietary insect inclusion starting from the $\mathrm{Y}$ intercept $(\mathrm{Y}=2.36-0.008627 \mathrm{x}, \mathrm{x}=\%$ insect in diet, Figure 2A). The FCR plotted against insect inclusion in diets did not have a significant slope or breaking point detectable (Figure 2B). The digestibility of crude protein was also affected by insect inclusion in the diets, with a breaking point at $24.6 \%$ dietary insect inclusion (Figure 2C), while the digestibility of lipids was not affected by insects in the diets (Figure 2D). Since 95\% of the diets included in this study contained between zero and $40 \%$ insect ingredients, the strongest conclusions can be drawn in this area and larger insecurities of effect will be associated with performance of diets with insect ingredients above this level. The spread of data as seen in Figure 1A and in the non-linear regression analyses is an indication of other inherent variations such as aquaculture species, insect species or other criteria from the different studies included in the dataset.

A PCA was then performed to provide an overview of the complete dataset and the relationship between insect inclusion in the diets (spread from $0 \%$ to $76 \%$ of the diets) and the variable performance responses (FCR, SGR, DCP and DCL). The PCA (Figure 3) revealed that the performance responses in aquatic species fed diets containing between $4 \%$ and $30 \%$ insect ingredients were grouped together with the control groups ( $0 \%$ inclusion). Similar trends were observed for the data grouped into TL, namely $\mathrm{TL}>3.5, \mathrm{TL}<3.5$ and crustaceans. The PCA plot (Figure S2) confirmed that the three subgroups are clustered together towards low insect inclusion in the diets, where most of the data is found. The highest FCR and SGR were observed for subgroups having TL above 3.5 and below 3.5 , respectively. Overall, the PCA results showed that high levels of IM are not recommended for all aquafeed
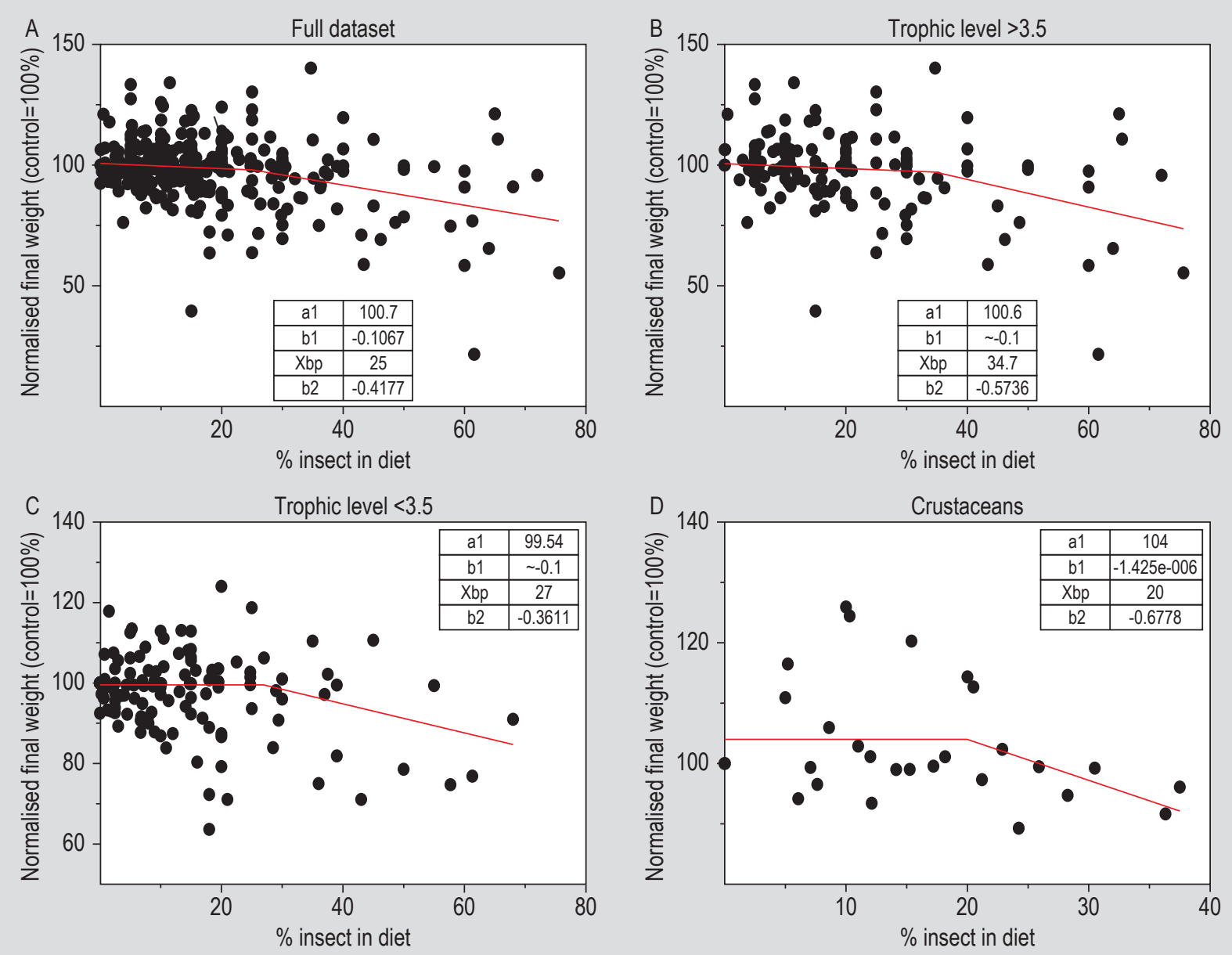

Figure 1. Broken line analysis of normalised weight gain against insect inclusion in the diet in (A) the full dataset and (B) data set divided by trophic levels (TL): $T L>3.5$, (C) TL<3.5 and (D) crustaceans. $a 1=$ intercept; $b 1=$ slope line 1; b2 = slope line 2; Xbp = $x$ at breaking point. 

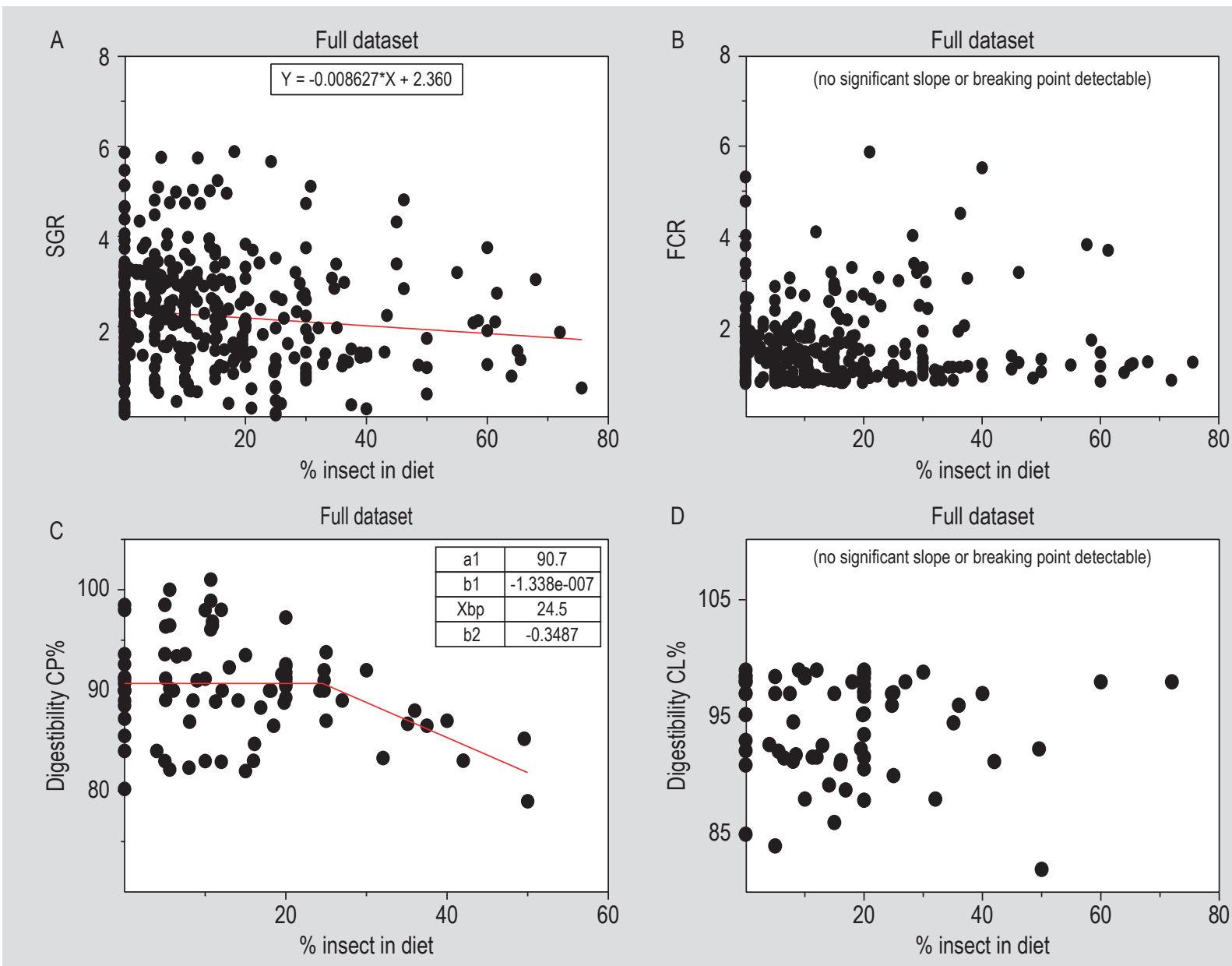

Figure 2. Linear regression and broken line analyses was performed on results on (A) specific growth rate (SGR); (B) feed conversion ratio (FCR); (C) digestibility of crude protein (CP); and (D) digestibility of crude lipid (CL), against percentage insect in diet in the full dataset, as well as in data separated into trophic levels. a1 = intercept; b1 = slope line 1; b2 = slope line 2; $\mathrm{Xbp}=\mathrm{x}$ at breaking point.

purposes and that levels in the range of 5-30\% might be regarded as appropriate to produce results in the range observed in control diets.

\section{Growth and performance of aquatic species subgroups}

The performance parameters (NFW, FCR, SGR, DCP and $\mathrm{DCL})$ of the three subgroups $(\mathrm{TL}>3.5, \mathrm{TL}<3.5$ and crustaceans) were analysed. There were breaking points detected in the normalised final body weight, at 34.7, 27 and $20 \%$ of insect inclusion in the diets for the aquatic species with TL $>3.5, \mathrm{TL}<3.5$ and crustaceans, respectively (Figures 1B, C and D, respectively). Similar clear breaking points were not seen for SGR (Figures S3B, S3C and S3D). For FCR, no breaking point was obtained for TL groups above and below 3.5 (Figures S4B and S4C); however there was a breaking point at $17.4 \%$ of insects in the diets for crustaceans (Figure S4D), with increasing FCR at higher insect inclusion than this. Further, clear breaking points were also detected for the digestibility of CP with the full dataset (24.6\% insects in diet, Figure $2 \mathrm{C}$ ) and for the group with TL above 3.5 (25.6\% insects in the diet, Figure S5C). In general, this comparative study of growth performance based on the TL of aquatic species and crustaceans, showed that aquatic species with a TL above 3.5 have a higher level of acceptance for dietary insect (35\%), than the aquatic species with TL below 3.5. The crustaceans had the lowest tolerance level of insects in the diet (20\%).

Of dietary components, saturated fats significantly decreased the normalised final body weights of the full dataset from a breaking point at 39\% SFA of total FA in the diets (Figure 4A). A similar trend was observed for lauric acid, with a significant decrease of the normalised final weight of the full data set from the breaking point at $26 \%$ C12\% of total FA in diet (Figure 4B). The same tendencies in reduction of normalised final body weight was seen in the aquatic species with TL $>3.5$ (breaking point at 38.6\% SFA of FA in diet, Figure S7B). Normalised final body weight of the same TL group was also decreased by increased lauric 


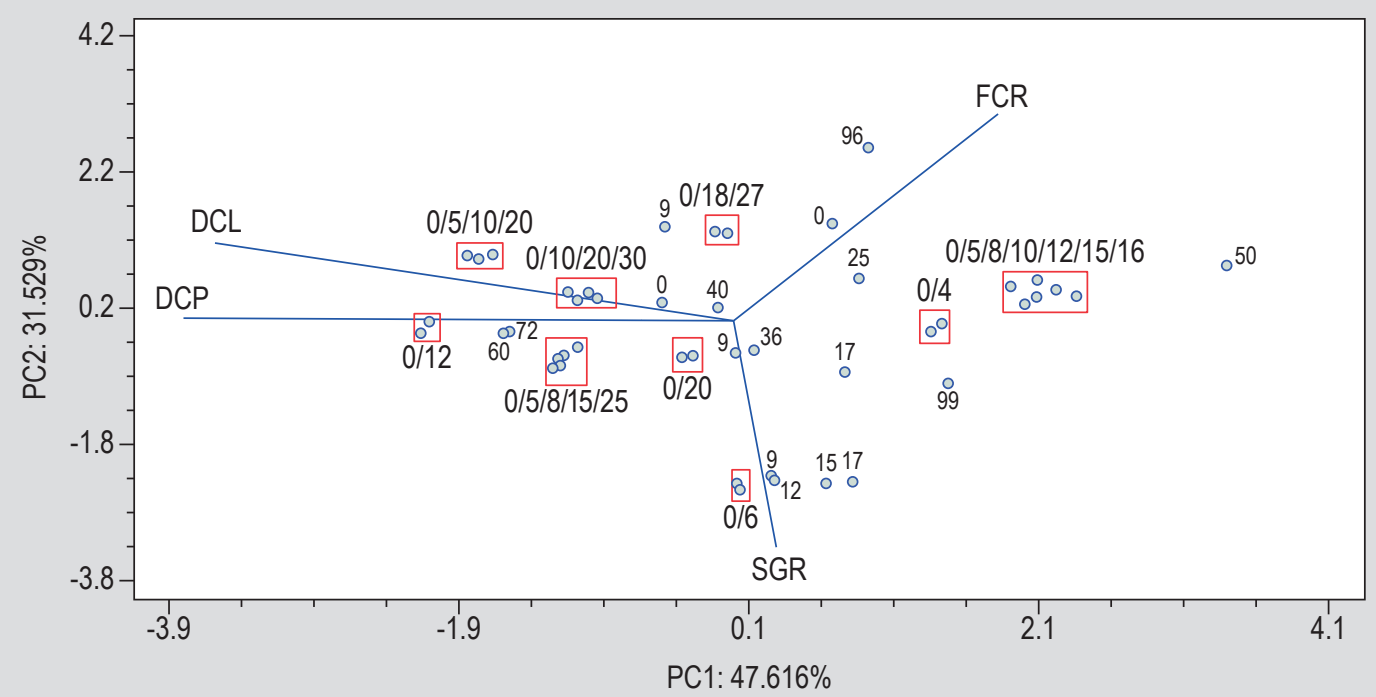

Figure 3. Principal component analysis (PCA) showing the relationship between percentage of insect inclusion in the diets (ID) and the performance outputs feed conversion ratio (FCR), specific growth rate (SGR), digestibility of crude protein (DCP) and digestibility of crude lipid (DCL) recorded in published studies. The 91 bibliographic references (Table S1) were arranged as a $415 \times 5$ matrix where the first column with 415 rows represents the ID (ranging from 0 to $76 \%$ ) and the remaining four columns represent the experimental responses (FCR, SGR, DCP and DCL). A total of two components (PC1 and PC2) were able to explain a $79.145 \%$ of the data variability and detect specific insect inclusion diets that exhibited a similar performance to control diets. The red rectangles indicate those insect inclusion diets that were clustered with the control diets and the slash-separated numbers the control $(0 \%)$ and nominal percentage of ID associated to every cluster.

acid in the diets $(\mathrm{Y}=98.77-0.53 \mathrm{x}, \mathrm{x}=\% \mathrm{C} 12 \%$ of $\mathrm{FA}$ in diet, Figure S8B), while the other performance indicators (FCR, DCP, DCL, SGR) were not affected (data not shown). The relation between saturated fats or lauric acid in diet and decreased final body weight was not seen in the group of aquatic species with $\mathrm{TL}<3.5$ (Figures $\mathrm{S} 7 \mathrm{C}$ and $\mathrm{S} 8 \mathrm{C}$ ). This is, however, most likely due to lower levels of SFA and lauric acid used in diets in this trophic group, with few dietary groups above the breaking point detected for the group with TL above 3.5 (Figures S7C and S8C). For the subgroup of data from studies using insect ingredients in trials on crustaceans, there was no data available (Figures S7D and S8D). Increased content of saturated fats in insectbased diets, especially related to the increased lauric acid content in BSF ingredients, may therefore reduce growth performance of the aquatic species. This should be given extra attention in studies where high contents of this insect species is used, especially when full-fat insect products are used.

\section{Impact of insect species subgroups on growth performances}

The performance of aquaculture species was divided into two subgroups depending on the insect species they were fed (BSF or MW). For BSF, the main effect of increased insect inclusion was on NFW (Figure 5A). The calculated breaking point was located at $40 \% \mathrm{BSF}$ inclusion in the diets. There was a slow but gradual decrease in NFW from 0 to $40 \%$ BSF inclusion, which was changed to a strong decrease after this point. There was also a reduction in SGR with increased BSF in diet, but the relation was not very strong and there was not a breaking point detected $(y=2.469-$ $0.015 x, x=\%$ insects in diet, Figure $5 C$ ). This decrease in normalised final weight might be due to increased lauric acid content, since a significant linear relationship between final body weight and dietary lauric acid was also found in the BSF-fed aquatic species (data not shown). It is, however, difficult to separate these two factors due to the natural contribution of C12:0 in BSF. In aquafeeds containing MW, a similar decrease as in BSF fed aquatic species was seen, but only in SGR $(Y=2.9-0.03 x, x=\%$ insects in diet, Figure 5D), not in final weight (Figure 5B). Since there were only few values with high weights in this dataset on MW, we excluded the data on fish weighing more than $500 \mathrm{~g}$ in these analyses. This was to reduce bias due to fish size, which will affect the SGR. There was no effect of BSF or MW inclusion on FCR (data not shown).

Similar results were seen in the recent meta-analysis done by Hua (2021), where inclusion levels of BSF larvae higher than $29 \%$ in the diets resulted in a poorer growth (SGR) than aquatic species fed FM control diets, while dietary inclusion of MW at any level did not reduce growth of aquatic species. The current study revealed a reduced performance in both BSF and MW fed aquatic species, but a bit differently. The reduction in SGR in aquatic species fed MW was more immediate than with the introduction of BSF, which kept quite stable till $\sim 40 \%$ inclusion levels. 

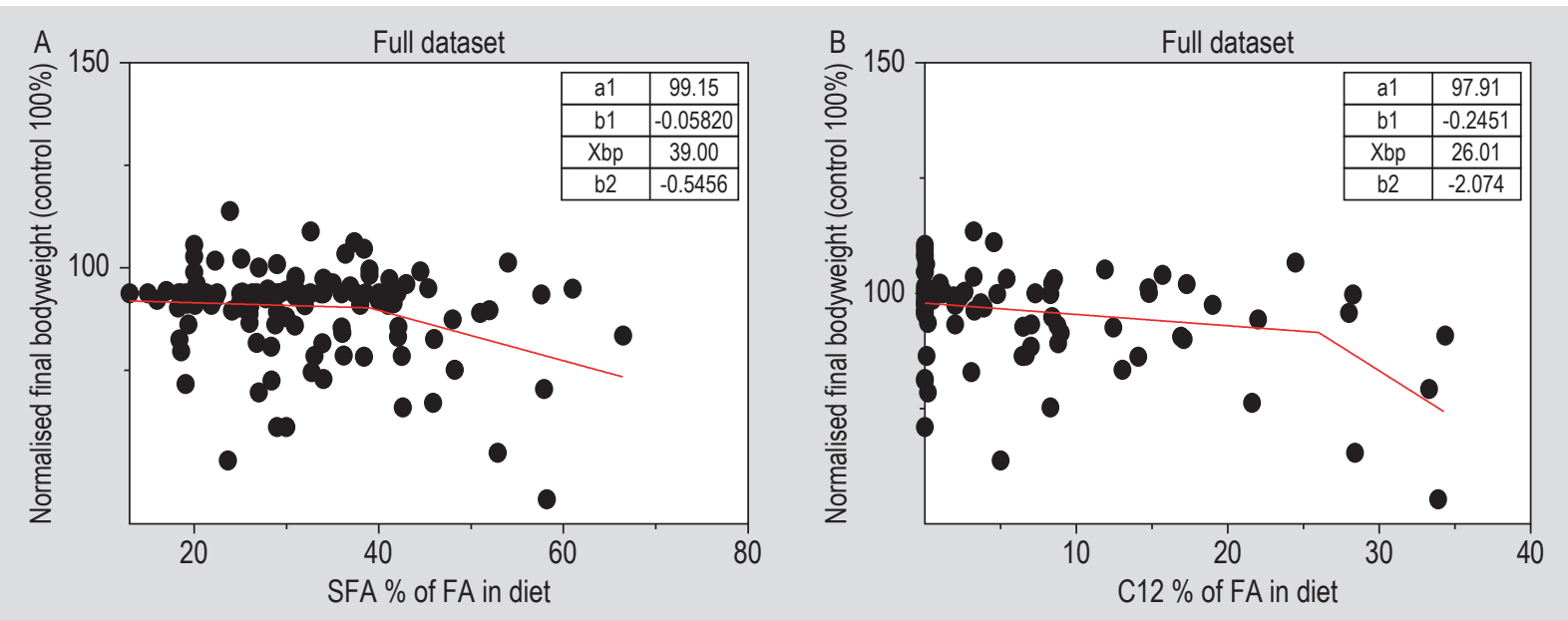

Figure 4. Broken line analysis of the normalised final body weight plotted against (A) dietary saturated fats (SFA) and (B) dietary C12:0 lauric acid for the full dataset. Data divided into the three trophic groups is presented in Figures S7 and S8. a1 = intercept; b1 = slope line 1; b2 = slope line 2; Xbp = $x$ at breaking point.
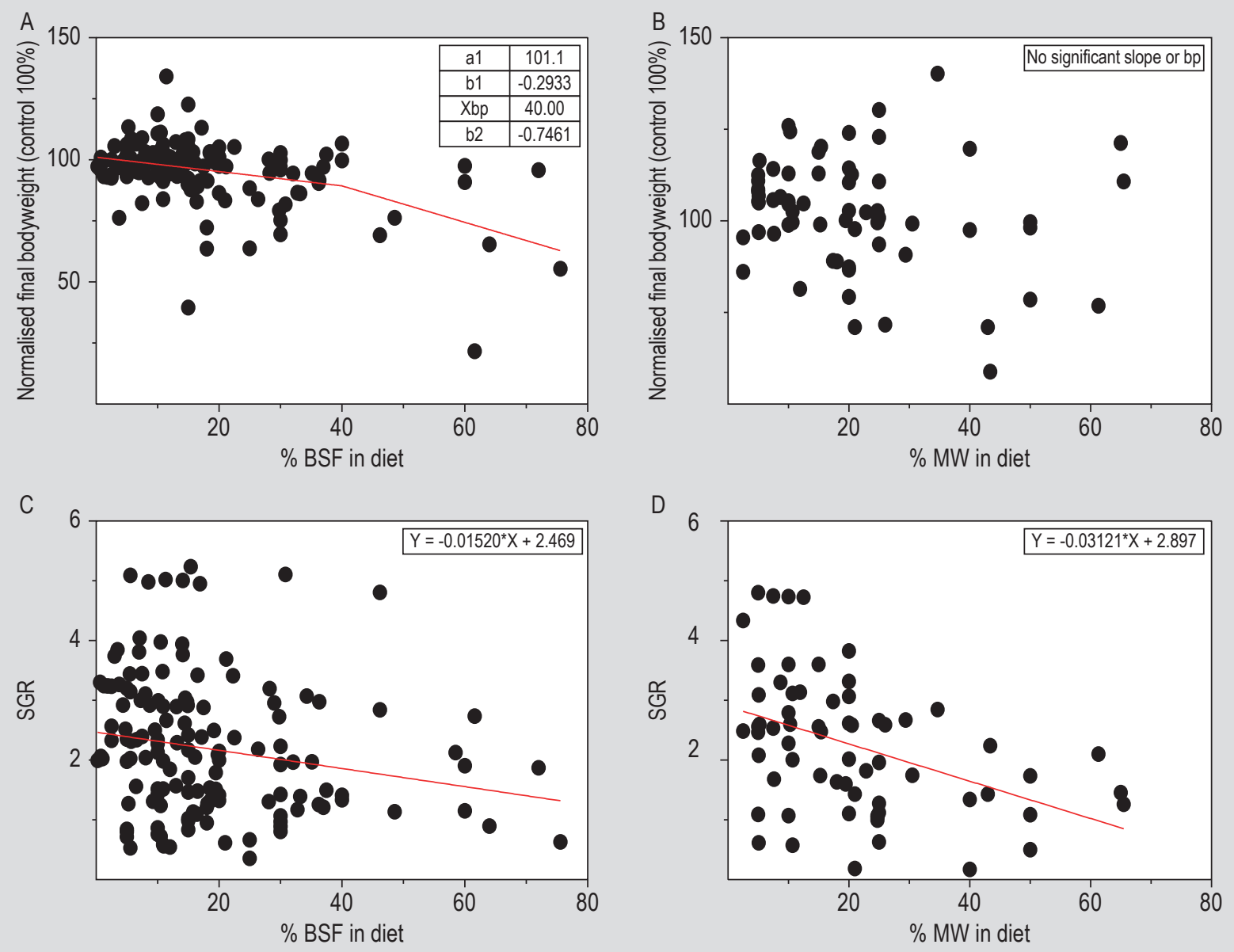

Figure 5. Linear regression of normalised final body weight and specific growth rate (SGR) plotted against percent inclusion of black soldier fly (BSF) (A and C) and mealworm (MW) (B and D) in aquafeeds. a1 = intercept; b1 = slope line 1; b2 = slope line 2; $\mathrm{Bp}=$ breaking point; $\mathrm{Xbp}=\mathrm{x}$ at breaking point. 
However, with no significant reduction in final weights, only in SGR, when increasing MW content in aquafeeds, a more detailed study of individual species etc. would have to be done to elucidate on this topic. BSF larvae and MW contain approximatively the same level of crude protein ( 47 and $50 \%$, respectively) and fat (24 and $22 \%$, respectively), but the FA profile differs largely between the two species (Nogales-Mérida et al., 2019). Thus, the divergent effects of BSF and MW on animal growth might be due to the FA profile but also related to nutrient digestibility or presence of antinutritional factors.

\section{Making an optimal insect-containing aquafeed}

\section{Estimation of crude protein in insect meals}

The protein requirement varies between aquatic species and their life stages. Generally spoken, carnivorous fish and shellfish used in aquaculture, often marine, usually have higher protein requirements (38-55\% protein of diet) than omnivores (20-40\%) (NRC, 2011). The protein content of the diets included in this meta-analysis were mostly covering the requirements of the cultured animal. The dietary protein content is, however, almost exclusively reported as crude protein calculated by using the standard 6.25 N-to-protein factor. The problem with this is that insects contain high concentrations of non-protein nitrogen and the protein content is therefore often overestimated by using this factor, as reported earlier (Janssen et al., 2017; Liland et al., 2017). It has been proposed to use nitrogen-toprotein conversion factors of 4.76 for BSF larvae, MW and lesser MW, and between 4.53-4.80 for house cricket meals (Belghit et al., 2019b; Janssen et al., 2017). These factors provide a more correct estimate of IM protein content, which is a vital determinant when insects are to replace other protein sources in aquafeed. Of the 91 articles selected for this meta-analysis, only two used a corrected protein factor. Some trials reporting reduced growth due to the introduction of IMs to the diets, may in fact be reporting a change in performance due to lack of dietary protein. The general trend is, however, an increased crude protein content in the diets with increased insect inclusion (crude protein $=41.9+0.07 \mathrm{x}, \mathrm{x}=\%$ insects in the diets, $P=0.006$, $R^{2}=0.02$, data not shown), suggesting that many experiments have, in fact, considered the overestimation of crude protein content when using the standard $6.25 \mathrm{~N}$-to protein factor in their diet formulations. The information from the included studies suggests that future studies should consider the substantial amounts of non-protein nitrogen in IM and use alternative conversion factors more suited for these protein sources.

\section{Effects of supplementing dietary amino acids}

When using an alternative protein source in aquafeed, it is essential to have precise and quantitative data on the dietary content of essential AAs, as many protein sources of non-animal origin have an unbalanced composition of these. In a setting of commercial aquaculture, limiting AAs would be added to the aquafeeds and should therefore also be supplemented in experiments to fill the requirements of the species. The general AA profile of IM varies according to species and are taxon dependent, with the Diptera having a similar profile to FM, while the Celeoptera and Orthoptera have a close profile to soybean meal and are generally deficient in methionine and lysine (Henry et al., 2015). The growth and performance of rainbow trout and seatrout were analysed together while seabass and seabream were analysed together and are presented in Figure 6. Dietary supplementation of limiting AAs did not affect the normalised final body weight in either of the two groups of aquatic species (seabass/seabream and trout, Figure $6 \mathrm{~A}$ and $6 \mathrm{~B}$, respectively). The FCR in the supplemented trout did increase with increased insect inclusion in the diets (Figure 6D), but since these diets all clustered around 0-20\% inclusion levels, this could level out at higher inclusion levels, as seen in the AA supplemented diets. There was no linear relationship between the SGR of the aquatic species and the dietary inclusion of insects (Figures 6C and D). The AA-supplemented diets led to a higher SGR in both groups of species (Figures 6E and 6F). Supplementing with limiting AAs also led to a lower FCR in seabass/seabream (Figure 6C). It must be noted that all the diets, supplemented or not, fulfilled the requirement of the respective species. The effect of dietary lysine, arginine, leucine and phenylalanine on FCR and SGR were clearly visible in different subset of data (data not presented due to no clear relation between these AA contents in diets and insect inclusion), so being aware of the positive effects of adequate AA contents of the diets is of great importance, as expected. The overall quality of the aquafeed might be the most important factor when planning a trial using insect ingredients, possibly explaining why some experiments fail to make the animals perform optimally on these feeds, while some experiments succeed.

\section{Estimation of chitin in insect meals}

Chitin is the primary structural polysaccharide of the arthropod exoskeleton. Insects are known to contain acid detergent fibre (ADF) and neutral detergent fibre and these fibres represent chitin. Whole insects contain between $5-25 \%$ chitin, with $35 \%$ of chitin only in the exoskeletons from BSF larvae (Hahn et al., 2018). The content of chitin was reported only in a few studies in the collected data and varied considerably between IMs. For example, chitin was reported to be $2.7-16.6,2.8-22.6$ and $9.2-16.7 \%$ of dried IM for BSF, MW and silkworm meals, respectively. 

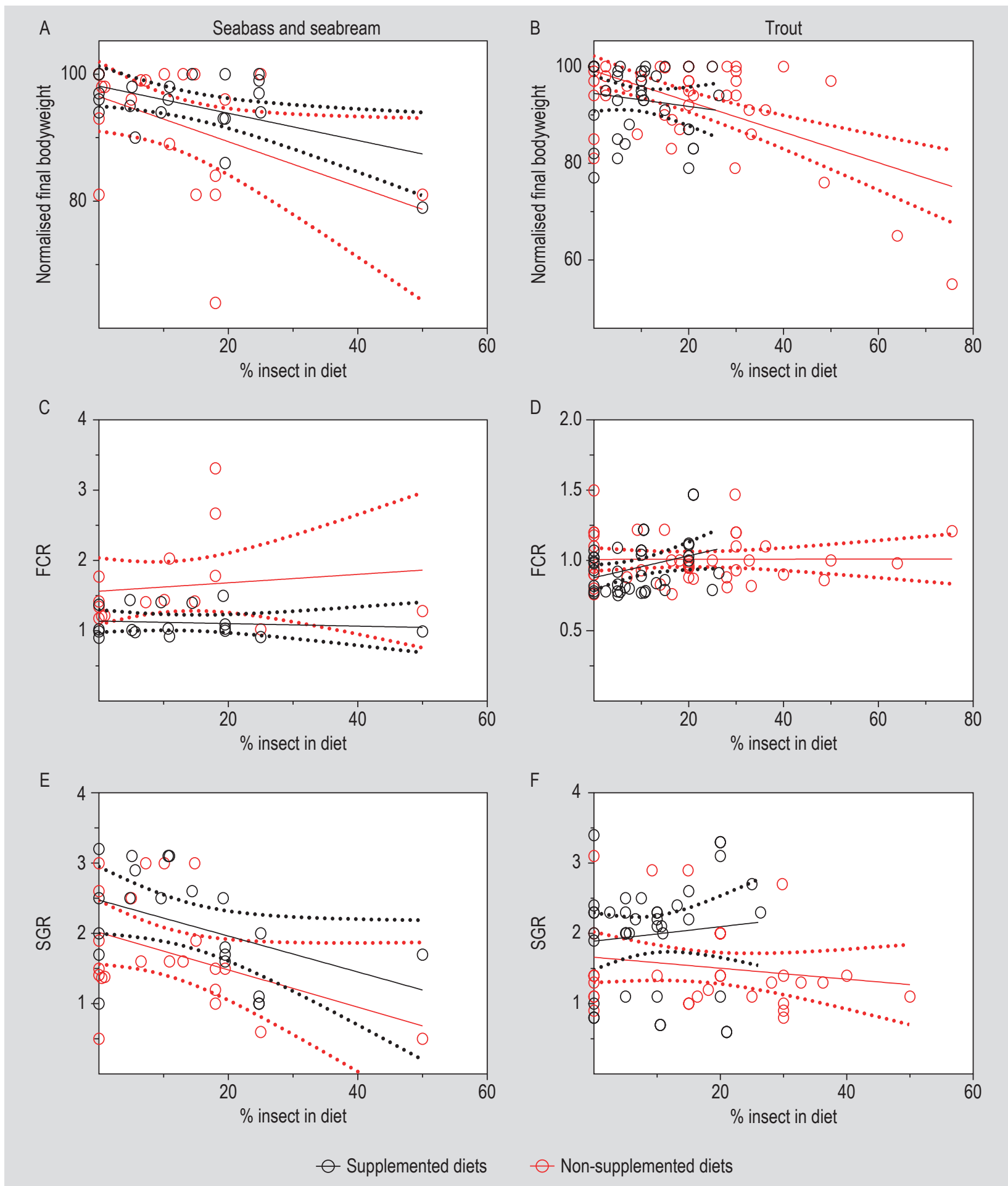

Figure 6. Normalised final body weight (control set to $100 \%$ ), feed conversion ratio (FCR) and specific growth rate (SGR) plotted against the percentage inclusion of insects in diet in seabass and seabream ( $A, C$ and $E$ ) and trout (B, D and F). Data from trials using supplemented diets (and its best-fit line and $95 \%$ confidence interval) are shown in black, while the non-supplemented diets are shown in red.

In these studies, two main methods were reported for chitin quantification in IM, namely ADF and $\mathrm{N}$ - acetyl glucosamine estimation. Finke (2007) demonstrated that the $\mathrm{ADF}$ fraction contains a high amount of AA, which leads to an overestimation of insect chitin content as ADF contains both protein and chitin. Furthermore, according to Clark et al. (1993) N-acetyl glucosamine estimation (NAG) was used as an indicator of chitin digestion based on the calorimetric 
method (Reissig et al., 1955). This method was adopted by Alves et al. (2020) for estimating the chitin content. Also, studies conducted by Marono et al. (2015) calculated chitin considering the protein linked to acid detergent fibre (AOAC, 2003). However, these calculated values could underestimate the true amount of chitin in different IMs. Up to date, it seems that the quantification of chitin is still challenging, since this polymer is always associated with other compounds (protein, carbohydrates, lipids or minerals) in IMs. Furthermore, chitin is a hard, inelastic, $\mathrm{N}$-acetylated amino polysaccharide and it is insoluble in water and most solvents, making direct quantification of chitin very challenging. There are, however, new methods being developed which could be useful for future studies, for example by using calcofluor staining (Henriques et al., 2020). An important note is to find a method that is easily accessible and that could be generally agreed on as the benchmark chitin method for better comparison between trials.

Which factors reduce crude protein digestibility of animals fed insect-based diets?

Meta-analysis of protein digestibility data (by both nonlinear regression and PCA) revealed that the digestibility of crude protein declined in diets containing more than $25 \%$ insects. Considering the insect inclusion thresholds for uncompromised growth of 10 to $37 \%$ (by non-linear regression) and 5 to $30 \%$ (by PCA), it can be inferred that protein digestibility is an important factor, influencing the growth performance of aquatic species fed insect-containing diets. Altered growth of aquatic species fed insect-based ingredients related to reduction of the bioavailability and digestibility of nutrients are often attributed to the content of chitin in IMs (Gasco et al., 2019; Kroeckel et al., 2012). Inclusion of dietary chitin in aquafeeds without negative effects on growth performances and digestibility of diets has been successfully demonstrated in some fish feeding trials (Fines and Holt, 2010; Gopalakannan and Arul, 2006; Karlsen et al., 2017), but not in others (Shiau and Yu, 1999). It has been reported that the structural form of chitin inhibits nutrient absorption from the intestinal tract and therefore reduces protein and lipid bioavailability in mice and poultry (Han et al., 1999; Tanaka et al., 1997). In this meta-analysis, it was, however, not possible to look for a correlation between the content of chitin in the feeds and the digestibility of protein or lipids due to the very limited data and large variations in analytical methods used for chitin measurements. Recently, Fisher et al. (2020) showed that the digestibility of dietary BSF was higher than diets using soy protein concentrate, corn protein concentrate or FM as a protein source in Atlantic salmon. However, when comparing the digestibility of BSF and MW in the diets of European seabass, MW-containing feeds had higher protein and AA digestibility than diets with BSF (Basto et al., 2020). The authors speculated that the difference in digestibility between BSF and MW could be caused by the chitin, which was higher in the BSF meal than the MW meal (6.2\% and 4.6\% of meals, respectively) (Basto et al., 2020). It is, however, also possible that this could have been cause by other factors in the BSF, like lauric acid or other compounds not yet described. Some studies have also shown that the processing of BSF can improve protein digestibility, such as BSF hydrolysate protein having higher protein digestibility compared to defatted insect protein meal (Roques et al., 2020). Different methods to process BSF meals have also been shown to strongly affect growth in trials with Atlantic salmon (Lock et al., 2016). The processing method may therefore have a great impact on the bioavailability of both AAs and FAs (Dumas et al., 2018; Roques et al., 2020). Based on the limited available data, it is not possible to conclude which factors reduce crude protein digestibility of aquatic species fed insectbased diets. More research is needed to be able to pinpoint which components of the IMs are causing this decline in protein digestibility.

\section{Conclusions}

The analysis of the compiled information on diet composition and performance of 415 experimental diets, reported in 91 different publications, allows formulating diets containing up to $25-30 \%$ insect inclusion without reduced performance of the aquaculture species. The main limitations for the use of insects as feed ingredients might be the high variation in quality and compositions of IMs as well as large changes in dietary fatty acid profiles of the diets when using non-defatted meals and insect oils. There should also be specific use of true protein for the assessment of protein in insect-containing diets. Given the high degree of data heterogeneity, the results have been interpreted cautiously by different mathematical/ statistical approaches. For example, there is a general lack of data on aquacultured species up to market size, with much of the data coming from studies done on juvenile stages. However, the information from the 91 analysed references might be regarded as the core evidence on this topic to date, and along with the present meta-analysis may allow for corresponding improvements to future research.

\section{Acknowledgments}

This study was supported by Nærings- og fiskeridepartementet, IMR and fellowship provided by the Indian Council of Agricultural Research (ICAR) through the ICAR Netaji Subash International Fellowship.

\section{Conflicts of interest}

No potential conflicts of interest were reported by the authors. 


\section{Supplementary material}

Supplementary material can be found online at https://doi. org/10.3920/JIFF2020.0147.

Figure S1. Normal distribution of data from the control group (red circles) and insect-diet groups (black circles) in terms of the performance parameters feed conversion ratio (FCR), specific growth rate (SGR), digestibility of crude protein (DCP) and digestibility of crude lipid (DCL).

Figure S2. Principal component analysis showing the relationship between percentage of insect inclusion in the diets (ID) and (A) FCR and SGR and (B) DCP and DCL.

Figure S3. Relation between specific growth rate (SGR) and $\%$ insect in diet in the full data set (A), trophic level $>3.5$ (B), trophic level $<3.5$ (C) or in crustaceans (D).

Figure S4. Relation between feed conversion ratio (FCR) and the \% of insects in the diets in the full dataset (A), trophic level $>3.5$ (B), trophic level $<3.5$ (C) or in crustaceans (D9.

Figure S5. Relation between digestibility of crude protein (CP) and \% insect in diet at $24.57 \%$ insect in diet for the full data set (A).

Figure S6. Relation between digestibility of crude lipid $\%$ and the $\%$ of insects in the diets in the full dataset (A), trophic level $>3.5$ (B), or trophic level <3.5 (C).

Figure S7. Relation between content of saturated fatty acids (SFA) and normalised final body weight.

Figure S8. Relation between content of lauric acid (C12\% of fatty acid (FA) in diet and normalised final body weight in the full dataset (26\% of total FA) (A) and in the trophic level >3.5 (B), respectively.

Table S1. Full dataset.

Table S2. Fish species included in studies.

Table S3. Overview of insect species and products used in feeding trials included in meta-analysis.

\section{References}

Abdel-Tawwab, M., Khalil, R.H., Metwally, A.A., Shakweer, M.S., Khallaf, M.A. and Abdel-Latif, H.M.R., 2020. Effects of black soldier fly (Hermetia illucens L.) larvae meal on growth performance, organs-somatic indices, body composition, and hemato-biochemical variables of European sea bass, Dicentrarchus labrax. Aquaculture 522: 735136. https://doi.org/10.1016/j.aquaculture.2020.735136
Alves, A.P.d.C., Paulino, R.R., Pereira, R.T., Da Costa, D.V. and e Rosa, P.V., 2020. Nile tilapia fed insect meal: growth and innate immune response in different times under lipopolysaccharide challenge. Aquaculture Research 52: 529-540. https://doi.org/10.1111/are.14911

Arru, B., Furesi, R., Gasco, L., Madau, F.A., Pulina, P., 2019. The introduction of insect meal into the fish diet: the first economic analysis on European sea bass farming. Sustainability 11: 1697. https://doi.org/10.3390/su11061697

Association of Official Analytical Chemists (AOAC), 2003. Official methods of analysis, $17^{\text {th }}$ edition. AOAC, Washington, DC, USA.

Basto, A., Matos, E. and Valente, L.M.P., 2020. Nutritional value of different insect larvae meals as protein sources for European sea bass (Dicentrarchus labrax) juveniles. Aquaculture 521: 735085. https://doi.org/10.1016/j.aquaculture.2020.735085

Belghit, I., Liland, N.S., Gjesdal, P., Biancarosa, I., Menchetti, E., Li, Y., Waagbø, R., Krogdahl, A. and Lock, E.-J., 2019a. Black soldier fly larvae meal can replace fish meal in diets of sea-water phase Atlantic salmon (Salmo salar). Aquaculture 503: 609-619. https:// doi.org/10.1016/j.aquaculture.2018.12.032

Belghit, I., Lock, E.-J., Fumière, O., Lecrenier, M.-C., Renard, P. Dieu, M., Berntssen, M.H.G., Palmblad, M. and Rasinger, J.D., 2019b. Species-specific discrimination of insect meals for aquafeeds by direct comparison of tandem mass spectra. Animals 9: 222. https:// doi.org/10.3390/ani9050222

Bondari, K. and Sheppard, D.C., 1981. Soldier fly larvae as feed in commercial fish production. Aquaculture 24: 103-109. https://doi. org/10.1016/0044-8486(81)90047-8

Bruni, L., Randazzo, B., Cardinaletti, G., Zarantoniello, M., Mina, F., Secci, G., Tulli, F., Olivotto, I. and Parisi, G., 2020. Dietary inclusion of full-fat Hermetia illucens prepupae meal in practical diets for rainbow trout (Oncorhynchus mykiss): lipid metabolism and fillet quality investigations. Aquaculture 529: 735678. https:// doi.org/10.1016/j.aquaculture.2020.735678

Cadinu, L.A., Barra, P., Torre, F., Delogu, F. and Madau, F.A., 2020. Insect rearing: potential, challenges, and circularity. Sustainability 12: 4567. https://doi.org/10.3390/su12114567

Clark, D.J., Lawrence, A.L. and Swakon, D.H.D., 1993. Apparent chitin digestibility in penaeid shrimp. Aquaculture 109: 51-57. https://doi. org/10.1016/0044-8486(93)90485-H

Cummins, V.C., Rawles, S.D., Thompson, K.R., Velasquez, A., Kobayashi, Y., Hager, J. and Webster, C.D., 2017. Evaluation of black soldier fly (Hermetia illucens) larvae meal as partial or total replacement of marine fish meal in practical diets for Pacific white shrimp (Litopenaeus vannamei). Aquaculture 473: 337-344. https:// doi.org/10.1016/j.aquaculture.2017.02.022

Devic, E., Leschen, W., Murray, F. and Little, D.C., 2017. Growth performance, feed utilization and body composition of advanced nursing Nile tilapia (Oreochromis niloticus) fed diets containing black soldier fly (Hermetia illucens) larvae meal. Aquaculture Nutrition 24: 416-423. https://doi.org/10.1111/anu.12573

Dumas, A., Raggi, T., Barkhouse, J., Lewis, E. and Weltzien, E., 2018. The oil fraction and partially defatted meal of black soldier fly larvae (Hermetia illucens) affect differently growth performance, feed efficiency, nutrient deposition, blood glucose and lipid digestibility of rainbow trout (Oncorhynchus mykiss). Aquaculture 492: 24-34. https://doi.org/10.1016/j.aquaculture.2018.03.038 
European Union (EU), 2017. Commission Regulation (EU) 2017/893 of 24 May 2017 amending Annexes I and IV to Regulation (EC) No 999/2001 of the European Parliament and of the Council and Annexes X, XIV and XV to Commission Regulation (EU) No $142 / 2011$ as regards the provisions on processed animal protein. Official Journal of the European Union L 138: 92. Available at: https://tinyurl.com/uzt956aw.

Evans, J., Alemu, M.H., Flore, R., Frøst, M.B., Halloran, A., Jensen, A.B., Maciel-Vergara, G., Meyer-Rochow, V.B., Münke-Svendsen, C., Olsen, S.B., Payne, C., Roos, N., Rozin, P., Tan, H.S.G., Van Huis, A., Vantomme, P. and Eilenberg, J., 2015. 'Entomophagy': an evolving terminology in need of review. Journal of Insects as Food and Feed 1: 293-305. https://doi.org/10.3920/JIFF2015.0074

Fabrikov, D., Sánchez-Muros, M.J., Barroso, F.G., Tomás-Almenar, C., Melenchón, F., Hidalgo, M.C., Morales, A.E., RodriguezRodriguez, M. and Montes-Lopez, J., 2020. Comparative study of growth performance and amino acid catabolism in Oncorhynchus mykiss, Tinca tinca and Sparus aurata and the catabolic changes in response to insect meal inclusion in the diet. Aquaculture 529: 735731. https://doi.org/10.1016/j.aquaculture.2020.735731

Fawole, F.J., Adeoye, A.A., Tiamiyu, L.O., Ajala, K.I., Obadara, S.O. and Ganiyu, I.O., 2020. Substituting fishmeal with Hermetia illucens in the diets of African catfish (Clarias gariepinus): effects on growth, nutrient utilization, haemato-physiological response, and oxidative stress biomarker. Aquaculture 518: 734849. https://doi.org/10.1016/j. aquaculture.2019.734849

Fines, B.C. and Holt, G.J., 2010. Chitinase and apparent digestibility of chitin in the digestive tract of juvenile cobia, Rachycentron canadum. Aquaculture 303: 34-39. https://doi.org/10.1016/j. aquaculture.2010.03.010

Finke, M.D., 2007. Estimate of chitin in raw whole insects. American Zoo and Aquarium Association 26: 105-115. https://doi.org/10.1002/ zoo.20123

Fisher, H.J., Collins, S.A., Hanson, C., Mason, B., Colombo, S.M. and Anderson, D.M., 2020. Black soldier fly larvae meal as a protein source in low fish meal diets for Atlantic salmon (Salmo salar). Aquaculture 521: 734978. https://doi.org/10.1016/j.aquaculture.2020.734978

Food and Agriculture Organization of the United Nations (FAO), 2011. FAOSTAT statistical database. FAO, Rome, Italy.

Food and Agriculture Organization of the United Nations (FAO), 2020. The state of world fisheries and aquaculture 2020. Sustainability in action. FAO, Rome, Italy.

Froese, R. and Pauly, D. (eds.), 2019. FishBase. Available at: www. fishbase.org.

Gasco, L., Biasato, I., Dabbou, S., Schiavone, A. and Gai, F., 2019. Animals fed insect-based diets: state-of-the-art on digestibility, performance and product quality. Animals 9: 170. https://doi. org/10.3390/ani9040170

Gasco, L., Henry, M., Piccolo, G., Marono, S., Gai, F., Renna, M., Lussiana, C., Antonopoulou, E., Mola, P. and Chatzifotis, S., 2016. Tenebrio molitor meal in diets for European sea bass (Dicentrarchus labrax L.) juveniles: growth performance, whole body composition and in vivo apparent digestibility. Animal Feed Science and Technology 220: 34-45. https://doi.org/10.1016/j. anifeedsci.2016.07.003
Gelinçek, İ. and Yamaner, G., 2020. An investigation on the gamete quality of Black Sea trout (Salmo trutta labrax) broodstock fed with mealworm (Tenebrio molitor). Aquaculture Research 51: 2379-2388. https://doi.org/10.1111/are.14581

Glencross, B.D., 2020. A feed is still only as good as its ingredients: an update on the nutritional research strategies for the optimal evaluation of ingredients for aquaculture feeds. Aquaculture Nutrition 6: 1871-1883. https://doi.org/10.1111/anu.13138

Glencross, B.D., Booth, M. and Allan, G.L., 2007. A feed is only as good as its ingredients - a review of ingredient evaluation strategies for aquaculture feeds. Aquaculture Nutrition 13: 17-34. https://doi. org/10.1111/j.1365-2095.2007.00450.x

Gopalakannan, A. and Arul, V., 2006. Immunomodulatory effects of dietary intake of chitin, chitosan and levamisole on the immune system of Cyprinus carpio and control of Aeromonas hydrophila infection in ponds. Aquaculture 255: 179-187. https://doi. org/10.1016/j.aquaculture.2006.01.012

Hahn, T., Roth, A., Febel, E., Fijalkowska, M., Schmitt, E., Arsiwalla, T. and Zibek, S., 2018. New methods for high-accuracy insect chitin measurement. Journal of the Science of Food and Agriculture 98: 5069-5073. https://doi.org/10.1002/jsfa.9044

Hale, O.J.G.E.S.J., 1973. Dried Hermetia illucens larvae (Diptera: Stratiomyidae) as a feed additive for poultry. Journal of the Georgia Entomological Society 8: 16-20.

Han, L.K., Kimura, Y. and Okuda, H., 1999. Reduction in fat storage during chitin-chitosan treatment in mice fed a high-fat diet. International Journal of Obesity 23: 174-179. https://doi. org/10.1038/sj.ijo.0800806

Henriques, B.S., Garcia, E.S., Azambuja, P. and Genta, F.A., 2020. Determination of chitin content in insects: an alternate method based on calcofluor staining. Frontiers in Physiology 11: 117. https:// doi.org/10.3389/fphys.2020.00117

Henry, M., Gasco, L., Piccolo, G. and Fountoulaki, E., 2015. Review on the use of insects in the diet of farmed fish: Past and future. Animal Feed Science and Technology 203: 1-22. https://doi.org/10.1016/j. anifeedsci.2015.03.001

Hu, J., Wang, G., Huang, Y., Sun, Y., He, F., Zhao, H. and Li, N., 2017. Effects of substitution of fish meal with black soldier fly (Hermetia illucens) larvae meal, in yellow catfish (Pelteobagrus fulvidraco) diets. Israeli Journal of Aquaculture - Bamidgeh 69.

Hua, K., 2021. A meta-analysis of the effects of replacing fish meals with insect meals on growth performance of fish. Aquaculture 530: 735732. https://doi.org/10.1016/j.aquaculture.2020.735732

Hua, K. and Bureau, D.P., 2012. Exploring the possibility of quantifying the effects of plant protein ingredients in fish feeds using metaanalysis and nutritional model simulation-based approaches. Aquaculture 356-357: 284-301. https://doi.org/10.1016/j. aquaculture.2012.05.003

Hua, K., Cobcroft, J.M., Cole, A., Condon, K., Jerry, D.R., Mangott, A., Praeger, C., Vucko, M.J., Zeng, C., Zenger, K. and Strugnell, J.M., 2019. The future of aquatic protein: implications for protein sources in aquaculture diets. One Earth 1: 316-329. https://doi. org/10.1016/j.oneear.2019.10.018 
International Platform of Insects for Food and Feed (IPIFF), 2019a. Building bridges between the insect production chain, research and policymakers. IPIFF, Brussels, Belgium. Available at: https:// ipiff.org/wp-content/uploads/2019/12/IPIFF-researchprioritiesHorizonEurope.pdf

International Platform of Insects for Food and Feed (IPIFF), 2019b. The European insect sector today: challenges, opportunities and regulatory landscape. IPIFF, Brussels, Belgium. Available at: https:// ipiff.org/wp-content/uploads/2019/12/2019IPIFF_VisionPaper_ updated.pdf

International Platform of Insects for Food and Feed (IPIFF), 2020a. Promoting insects for human consumption and animal feed. IPIFF, Brussels, Belgium.

International Platform of Insects for Food and Feed (IPIFF), 2020b. Edible insects on the Euopean market (factsheet). IPIFF, Brussels, Belgium. Available at: https://ipiff.org/wp-content/uploads/ 2020/06/10-06-2020-IPIFF-edible-insects-market-factsheet.pdf

Janssen, R.H., Vincken, J.-P., Van den Broek, L.A., Fogliano, V., Lakemond, C.M.J.J.o.A. and Chemistry, F., 2017. Nitrogen-toprotein conversion factors for three edible insects: Tenebrio molitor, Alphitobius diaperinus, and Hermetia illucens. Journal of Agricultural and Food Chemist 65: 2275-2278. https://doi. org/10.1021/acs.jafc.7b00471

Jeong, S.-M., Khosravi, S., Mauliasari, I.R. and Lee, S.-M., 2020. Dietary inclusion of mealworm (Tenebrio molitor) meal as an alternative protein source in practical diets for rainbow trout (Oncorhynchus mykiss) fry. Fisheries and Aquatic Sciences 23: 1-8. https://doi. org/10.1186/s41240-020-00158-7

Józefiak, A., Nogales-Mérida, S., Mikołajczak, Z., Rawski, M., Kierończyk, B. and Mazurkiewicz, J., 2019a. The utilization of fullfat insect meal in rainbow trout (Oncorhynchus mykiss) nutrition: the effects on growth performance, intestinal microbiota and gastrointestinal tract histomorphology. Annals of Animal Science 19: 747-765. http://doi.org/10.2478/aoas-2019-0020

Józefiak, A., Nogales-Merida, S., Rawski, M., Kieronczyk, B. and Mazurkiewicz, J., 2019b. Effects of insect diets on the gastrointestinal tract health and growth performance of Siberian sturgeon (Acipenser baerii Brandt, 1869). BMC Veterinary Research 15: 348. https://doi. org/10.1186/s12917-019-2070-y

Karlsen, Ø., Amlund, H., Berg, A. and Olsen, R.E., 2017. The effect of dietary chitin on growth and nutrient digestibility in farmed Atlantic cod, Atlantic salmon and Atlantic halibut. Aquaculture Research 48: 123-133. https://doi.org/10.1111/are.12867

Kaushik, S.J. and Seiliez, I., 2010. Protein and amino acid nutrition and metabolism in fish: current knowledge and future needs. Aquaculture Research 41: 322-332. https://doi.org/10.1111/j.13652109.2009.02174.x

Kroeckel, S., Harjes, A.G.E., Roth, I., Katz, H., Wuertz, S., Susenbeth, A. and Schulz, C., 2012. When a turbot catches a fly: evaluation of a pre-pupae meal of the black soldier fly (Hermetia illucens) as fish meal substitute - growth performance and chitin degradation in juvenile turbot (Psetta maxima). Aquaculture 364-365: 345-352. https://doi.org/10.1016/j.aquaculture.2012.08.041
Li, S., Ji, H., Zhang, B., Zhou, J. and Yu, H., 2017. Defatted black soldier fly (Hermetia illucens) larvae meal in diets for juvenile Jian carp (Cyprinus carpio var. Jian): growth performance, antioxidant enzyme activities, digestive enzyme activities, intestine and hepatopancreas histological structure. Aquaculture 477: 62-70. https://doi.org/10.1016/j.aquaculture.2017.04.015

Liland, N.S., Biancarosa, I., Araujo, P., Biemans, D., Bruckner, C.G., Waagbø, R., Torstensen, B.E. and Lock, E.-J., 2017. Modulation of nutrient composition of black soldier fly (Hermetia illucens) larvae by feeding seaweed-enriched media. PLoS ONE 12: e0183188. https://doi.org/10.1371/journal.pone.0183188

Lock, E.R., Arsiwalla, T. and Waagbø, R., 2016. Insect larvae meal as an alternative source of nutrients in the diet of Atlantic salmon (Salmo salar) postsmolt. Aquaculture Nutrition 22: 1202-1213. https://doi.org/10.1111/anu.12343

Magalhães, R., Sánchez-López, A., Leal, R.S., Martínez-Llorens, S., Oliva-Teles, A. and Peres, H., 2017. Black soldier fly (Hermetia illucens) pre-pupae meal as a fish meal replacement in diets for European seabass (Dicentrarchus labrax). Aquaculture 476: 79-85. https://doi.org/10.1016/j.aquaculture.2017.04.021

Marono, S., Piccolo, G., Loponte, R., Di Meo, C., Attia, Y.A., Nizza, A. and Bovera, F., 2015. In vitro crude protein digestibility of Tenebrio molitor and Hermetia illucens insect meals and its correlation with chemical composition traits. Italian Journal of Animal Science 14: 338-349. https://doi.org/10.4081/ijas.2015.3889

Muin, H., Taufek, N.M., Kamarudin, M.S. and Razak, S.A., 2017. Growth performance, feed utilization and body composition of nile tilapia, Oreochromis niloticus (Linnaeus, 1758) fed with different levels of black soldier fly, Hermetia illucens (Linnaeus, 1758) maggot meal diet. Iranian Journal of Fisheries Sciences 16: 567-577. Available at: http://jifro.ir/article-1-2721-en.html

National Research Council (NRC), 2011. Nutrient requirements of fish and shrimp. National Academies Press, Washington, DC, USA. https://doi.org/10.17226/13039

Newton, G.L., Booram, C.V., Barker, R.W. and Hale, O.M., 1977. Dried Hermetia Illucens larvae meal as a supplement for swine. Journal of Animal Science 44: 395-400. https://doi.org/10.2527/ jas $1977.443395 x$

Nogales-Mérida, S., Gobbi, P., Józefiak, D., Mazurkiewicz, J., Dudek, K., Rawski, M., Kierończyk, B. and Józefiak, A., 2019. Insect meals in fish nutrition. Reviews in Aquaculture 11: 1080-1103. https:// doi.org/10.1111/raq.12281

Prabhu, A.J.P., Schrama, J.W. and Kaushik, S.J., 2013. Quantifying dietary phosphorus requirement of fish - a meta-analytic approach. Aquaculture Nutrition 19: 233-249. https://doi.org/10.1111/ anu. 12042

Prabhu, A.J.P., Schrama, J.W. and Kaushik, S.J., 2016. Mineral requirements of fish: a systematic review. Reviews in Aquaculture 8: 172-219. https://doi.org/10.1111/raq.12090

Reissig, J.L., Strominger, J.L. and Leloir, L.F.J.J.o.B.C., 1955. A modified colorimetric method for the estimation of N-acetylamino sugars. Journal of Biological Chemistry 217: 959-966. https://doi. org/10.1016/S0021-9258(18)65959-9 
Roncarati, A., Cappuccinelli, R., Meligrana, M.C., Anedda, R., Uzzau, S. and Melotti, P., 2019. Growing trial of gilthead sea bream (Sparus aurata) juveniles fed on chironomid meal as a partial substitution for fish meal. Animals 9: 144. https://doi.org/10.3390/ani9040144 Roques, S., Deborde, C., Guimas, L., Marchand, Y., Richard, N., Jacob, D., Skiba-Cassy, S., Moing, A. and Fauconneau, B., 2020. Integrative metabolomics for assessing the effect of insect (Hermetia illucens) protein extract on rainbow trout metabolism. Metabolites 10: 83. https://doi.org/10.3390/metabo10030083

Sánchez-Muros, M.J., De Haro, C., Sanz, A., Trenzado, C.E., Villareces, S. and Barroso, F.G., 2015. Nutritional evaluation of Tenebrio molitor meal as fishmeal substitute for tilapia (Oreochromis niloticus) diet. Aquaculture Nutrition 22: 943-955. https://doi.org/10.1111/ anu. 12313

Shiau, S.-Y. and Yu, Y.-P., 1999. Dietary supplementation of chitin and chitosan depresses growth in tilapia, Oreochromis niloticus $\times O$. aureus. Aquaculture 179: 439-446. https://doi.org/10.1016/S00448486(99)00177-5

Sørensen, M., Berge, G.M., Thomassen, M.S., Ruyter, B., Hatlen, B., Ytrestøyl, T., Aas, T.S. and Åsgård, T.E.J.N.R., 2012. Today's and tomorrow's feed ingredients in Norwegian aquaculture Nofima rapportserie. Nofima AS. Available at: http://hdl.handle. net/11250/2557672
Tanaka, Y., Tanioka, S.-I., Tanaka, M., Tanigawa, T., Kitamura, Y., Minami, S., Okamoto, Y., Miyashita, M. and Nanno, M., 1997. Effects of chitin and chitosan particles on BALB/c mice by oral and parenteral administration. Biomaterials 18: 591-595. https:// doi.org/10.1016/S0142-9612(96)00182-2

Turchini, G.M., Trushenski, J.T. and Glencross, B.D.J.N.A.J.o.A., 2019. Thoughts for the future of aquaculture nutrition: realigning perspectives to reflect contemporary issues related to judicious use of marine resources in aquafeeds. North American Journal of Aquaculture 81: 13-39. https://doi.org/10.1002/naaq.10067

United Nations, 2019. Peace, dignity and equality on a health planet. UN, New York, NY, USA.

Van Huis, A., 2020a. Insects as food and feed, a new emerging agricultural sector: a review. Journal of Insects as Food and Feed 6: 27-44. https://doi.org/10.3920/JIFF2019.0017

Van Huis, A., 2020b. Prospects of insects as food and feed. Organic Agriculture 17: 1-8. https://doi.org/10.1007/s13165-020-00290-7 Wang, G., Peng, K., Hu, J., Yi, C., Chen, X., Wu, H. and Huang, Y., 2019. Evaluation of defatted black soldier fly (Hermetia illucens L.) larvae meal as an alternative protein ingredient for juvenile Japanese seabass (Lateolabrax japonicus) diets. Aquaculture 507: 144-154. https://doi.org/10.1016/j.aquaculture.2019.04.023

Wilfart, A., Espagnol, S., Dauguet, S., Tailleur, A., Gac, A. and GarciaLaunay, F., 2016. ECOALIM: a dataset of environmental impacts of feed ingredients used in French animal production. PLoS ONE 11: e0167343. https://doi.org/10.1371/journal.pone.0167343 
